\title{
Determinants of Adverse Birth Outcome in West Shewa Zone, Oromia Regional State, Ethiopia Hospital Based Unmatched Case-control Study
}

Daniel Belema Fekene ( $\square$ danibelema@gmail.com )

Department of Midwifery, College of Medicine and Health Sciences, Ambo University, Ambo, Ethiopia GIZACHEW ABDISSA BULTO

Ambo University

BINIYAM SEIFU WOLDEYES

Ambo University

GURMESA DABA DINA

Ambo University

KASSA MAMO NEGASH

Ambo University

Research article

Keywords: Determinant, Adverse birth outcome, West shewa zone, Ambo, Ethiopia

Posted Date: September 4th, 2020

DOl: https://doi.org/10.21203/rs.3.rs-65509/v1

License: (c) (i) This work is licensed under a Creative Commons Attribution 4.0 International License.

Read Full License 


\section{Abstract}

Back ground The adverse birth outcomes can lead to higher rates of illness and infection for newborns, as well as long-term neurological and health problems. Hence, this study aims to identify determinants of adverse birth outcomes among mothers who gave birth in hospitals in the west shewa zone, Ethiopia.

Methods Unmatched case-control study was conducted among 591 mothers (146 cases and 445 controls) who gave birth at hospitals found in the west Shewa zone from March 2020 and July 2020. All cases during the data collection period and every 3rd control after cases were selected as a study population. The data were collected from the mothers, measurements from neonates. The questionnaire template was coded by using open source software for Computer-Assisted Personal Interviewing using census and survey processing system (CS-Pro) version 7.1. The collected data were exported to SPSS version 23 for analysis. Finally, presented and interpreted at P-value $<0.05$ were considered as statistically significant in multivariable logistic regression.

Result: on multivariable analysis; urban residence ( $\mathrm{AOR}=0.56,95 \%, \mathrm{Cl}=0.36-0.88)$, lack of family support during child bearing (AOR=5.07, 95\%,Cl: 3.01-8.54), pregnancy type(3.994 (AOR=3.4, 95\%,Cl: 2.04-7.83,), short inter pregnancy interval ( $A O R=1.6,95 \% \mathrm{Cl}: 1.99-2.48)$, not provided all initial newborn care (AOR=2.19, 95\% Cl: 1.39-3.41), less than four antenatal care visits (AOR=1.6, 95\% Cl: 1.02-2.61) and having current obstetric complication ( $\mathrm{AOR}=2.7,95 \% \mathrm{Cl}$ : $1.55-4.84)$ were significantly associated with adverse birth outcomes.

Conclusions: Residence, lack of family support during child bearing, Pregnancy type, short inter pregnancy interval, not provided first initial newborn care, having current obstetric complications, and Number of ANC visits were identified as determinants of adverse birth outcome. Therefore, improving family support, inter-pregnancy interval through family planning counselling and provision, providing all initial newborn cares, and having the recommended ANC follow-up was recommended.

\section{Background}

An adverse birth outcome (ABOs), which includes preterm births (PTB) and low birth weight (LBW) are major drivers of morbidity and mortality in neonates and infants. ABOs is also an important contributor to serious, short and long term, physical and mental disabilities, including perinatal and infant death, chronic health problems later in life, such as hypertension, ischemic heart disease, metabolic syndrome, stroke, diabetes, malignancies, osteoarthritis, and dementia, learning difficulties, and hearing and visual impairments (1-4). Preterm is defined as babies born alive before 37 weeks of pregnancy are completed (5). Low birth weight is defined by the World Health Organization (WHO) as a weight of less than 2500 grams for a live-born infant at birth (6). A huge gap has been reported in birth outcomes between high income and low-income countries. Maternal mortality ratio is 100 -fold greater than maternal mortality in high-income countries in most high-income countries' pregnancies are planned, complications are reduced and birth outcomes are grossly favorable. The most severe adverse outcome of pregnancy is the 
death of the mother or her offspring (7-8). In the year of 2018 a total of 2.5 million children died in the first month of life globally. There are approximately 7000 newborn deaths every day, amounting to $47 \%$ of all under 5 year's mortality. Sub-Saharan Africa had the highest neonatal mortality rate at 28 deaths per 1,000 live births, followed by Central and Southern Asia with 25 deaths per 1,000 live births. A child born in sub-Saharan Africa is 10 times more likely to die in the first month of life than a child born in a highincome country (5).

Adverse birth outcomes are influenced by a different of biological, psychosocial and environmental factors. Different studies indicated that socioeconomic status, maternal education, marital status, pregnancy desire and teenage pregnancy, maternal co -morbidities and genetic vulnerabilities have also each been linked to poor pregnancy outcomes. Moreover, low pre-pregnancy body mass index (BMI), inadequate weight gain, and poor prenatal care utilization, female fetus, and self-reported cigarette smoking history are related to poor birth outcomes. A high level of anxiety and depressive symptoms among mothers has been associated with a higher risk of adverse birth outcomes (9-10).

In Ethiopia different studies have shown that the prevalence of adverse pregnancy outcomes is within the range of $13.9 \%-32.5 \%$. Low birth weight and prematurity were the common adverse birth outcomes reported and antenatal care follow-up, rural in residency, pregnancy-induced hypertension, advanced maternal age, having current complication of pregnancy, anemia and multiple pregnancy were factors associated with adverse birth outcomes (11-16). Though there are few studies conducted earlier in Ethiopia, those studies were cross sectional which is weak in identifying those factors and those studies were mainly conducted in single town or district. Additionally, there is no study conducted on determinants of ABOs in the study area. Therefore, the current study aimed at identifying the determinants of adverse birth outcomes in the study area by using unmatched case control study design.

\section{Methods}

\section{Study area and period}

The study was carried out in west Shewa zone, Oromia region, Ethiopia from March 2020 and July 2020. Ambo town is the capital of the zone and it is found at $114 \mathrm{~km}$ to the west of Addis Ababa. There are eight public Hospitals in the zone, 96 public health centres, 77 private clinics, 526 health posts. The zone has a total population of 2,058,676 of which are 1,030,175 women in 2018/2019 (zonal health office).

\section{Study design and population}

Hospital based unmatched case-control study design was carried out. All mothers who delivered at hospitals in west Shewa zone and their infants were our source population. All mothers who gave birth to low birth weight infant weighing less than $2500 \mathrm{gm}$ or gave birth at gestational age of less than 37 completed weeks, or stillbirth) were cases. Mothers who gave birth to an infant weighting greater than $2500 \mathrm{gm}$ or at term and live birth were considered as controls. 


\section{Sample size determination and Sampling procedure}

The sample size was calculated using EPI-Info 3.7.1 statistical software. Considering the proportion of complication during child birth of $55.8 \%$ among controls (16), odds ratio of 2.65 , confidence level of $95 \%$, power of $80 \%$, a case to control ratio of 1:2. The maximum sample size was 591 of which 197 were cases and 394 were controls. All government hospitals providing 24 hours delivery services in west Shewa zone were included in the study. The numbers of mothers were allocated to each hospital based on their last quarters institutional delivery performance report prior to data collection time. All women who gave birth to low birth weight infant weighing less than $2500 \mathrm{gm}$ or gave birth at gestational age of less than 37 completed weeks, or stillbirth) were included as cases. Controls were mothers who gave birth to an infant weighting greater than $2500 \mathrm{gm}$, or at term and live birth were selected every $3^{\text {rd }}$ after each case.

\section{Data collection tool, quality control and measurements}

A structured, interview administered questionnaire was prepared in English and translated into local language, Afan Oromo by the translator, and then translated back to English by a third person to check for consistency. The tool adapted from previous literature in different parts of the world and modified according to the local context $(7,13-17)$. The data were collected from the mothers, measurements from neonates. The questionnaire template was coded by using open source software for Computer Assisted Personal Interviewing using census and survey processing system (CS-Pro) version 7.1 and deployed to Census and survey entry (CS-Entry) android application. Eight nurses were recruited as data collectors and Assistant professors with a background of health professionals were hired as supervisors. In addition, the data collectors were trained for two days on the techniques of data collection and the purpose of the study for study participants before the start of data collection. Pre-test was done on $5 \%$ of the total study participant and necessary adjustment was made. The weight of the newborns was measured using a baby measuring weight scale to the nearest $100 \mathrm{~g}$ within $15 \mathrm{~min}$ after delivery.

\section{Operational Definition}

Pregnancy interval: It is the time elapsed between two consecutive pregnancies

Adverse birth outcome: in this study the adverse birth outcome was measured if least one or more of the following conditions in the current pregnancies occurred. These include women who gave birth to low birth weight infant weighing less than $2500 \mathrm{gm}$ or gave birth at gestational age of less than 37 completed weeks, or still birth.

\section{Data processing and analysis}


The data was collected and entered using CS-Entry for the android version and exported to SPSS version 23 for analysis. Multivariable logistic regression was done to determine determinants of adverse birth outcome. The goodness of fit of the model was checked using Hosmer-Lemen show test. All assumptions of logistic regression were checked. Collinearity of the variables was checked variance inflation factors (VIF) and tolerance. If $\mathrm{VIF}<10$ and tolerance $>0.1$ indicating that no multicollinearity among variables. Data was finally presented and interpreted at $\mathrm{P}$-value $<0.05$ were considered as statistically significant in multivariable logistic regression

\section{Ethical Consideration}

Ethical clearance was obtained from Ambo University ethical review Committee of College of medicine and health science with reference number CHMS/R/WM/04/2020.

\section{Results}

A total of 591 mothers (146 cases and 445 controls) were included with response rate of $100 \%$.Concerning educational status of mothers, $45(7.6 \%)$ of the cases are unable to read and write and $91(15.4 \%)$ of the controls are college and above. $124(21.0 \%)$ of the control were farmers and $45(7.6 \%)$ of the case were housewives on mother occupation. Majority of the cases $(15.7 \%)$ and the controls $(43.35 \%)$ were protestant by religion. Eighty four $(14.2 \%)$ of the cases and $170(28.8 \%)$ of the controls were living in rural (Table 1)

\section{Obstetric characteristics of participants}

Forty nine $49(8.3 \%)$ cases has history of one-time pregnancy and $115(19.5 \%)$ controls has greater or equals to four pregnancy. $118(20 \%)$ cases and $371(62.8 \%)$ their pregnancy was planned. Among the study participants $104(17.6 \%)$ cases and $288(48.7 \%)$ controls had used family planning. Majority of the participants of the study, $80(22 \%)$ of cases and $238(65.4 \%)$ controls had history of medical disorder. Among participants of the study $11(3 \%)$ cases and $30(8.3 \%)$ had history of previous obstetrics complications. One hundred twenty four $(21 \%)$ cases and $408(69 \%)$ controls have no current obstetrics complication. $58(9.8 \%)$ cases and 151 (25.5\%) controls females develop adverse birth outcome. (Table 2)

\section{Determinants of adverse birth outcome}

After controlling for confounders using multivariate analysis residence, lack of family support during child bearing, Pregnancy type, short inter pregnancy interval, not provided first initial newborn care, having current obstetric complications and Number of ANC visit were identified as determinants of adverse birth outcome. 
Mothers who live in urban areas fifty-six times less likely to develop adverse birth outcome when compared with rural living women ( $A O R=0.56,95 \%, \mathrm{Cl}=0.36-0.88$ ). The odds of having adverse birth out comes increases by two folds in mothers whose birth intervals are less than two years compared to their counterparts $(\mathrm{AOR}=1.57,95 \% \mathrm{Cl}=1.99-2.47)$. Furthermore, mothers who have no family support during child bearing had five times chance to develop adverse birth outcome when compared with mothers who had family support, $(\mathrm{AOR}=5.07,95 \% \mathrm{Cl}=3.01-8.54)$. Number of antenatal care follow-up was found to be associated with adverse birth outcome; in which mothers who had less than four antenatal care visits were two times more likely to develop adverse birth outcomes compared to their counterparts, $(A O R=1.63$ ,95\% Cl: 1.02-2.62). Mothers who gave birth to twins had four times chance to develop adverse birth outcomes compared to mothers who gave birth to singleton, $(\mathrm{AOR}=3.99,95 \% \mathrm{Cl}$ : 2.04-7.83). Also, the new borns who does not get initial new born care had two times chance to experience adverse birth outcomes compared to their counterparts, (AOR=2.18, 95\% Cl: 1.39-3.41). Having current obstetric complication three times more likely to develop adverse birth outcome when compared with no current obstetric complication (AOR=2.72, 95\% Cl: 1.55-4.82) (Table 3).

\section{Discussion}

This study tried to identify determinants of adverse birth outcome among mothers who delivered at public hospitals in west Shewa zone, Oromia region, Ethiopia. Women's place of residence was found to be significantly associated with adverse birth outcome. Those women residing in urban areas were found to be $56.2 \%$ less likely to experience adverse birth outcome than those in rural areas. Similar studies reported in china, Gamo Gofa, Hosana town and northern Wollo (17-20). This could be lack of access for quality pregnancy related cares, the accessibility of medical services, health information, and nutritional awareness which are more prominent in rural area.

Number of ANC follow up is significantly associated with adverse birth outcome, mothers who had history of less than four ANC visits were two times more likely to have ABOs than those who had more than four ANC visits. This finding is supported by study conducted Cameroon, India, Malawi, Addis Ababa, Tigrai region, Amahara region, North shewa zone, central Ethiopia (21-27). This might be due to the fact that those mothers who had four or more ANC visits have access to different health promotive and preventive interventions which are used to enhances health of both the mother and fetus.

Having current obstetric complication history was also found to significantly associate with adverse birth outcome. The chance of developing an abnormal birth outcome among mothers with current history of child-related abnormal birth outcome was by three times higher than those mothers without complication. A similar study conducted in Gambia and Nigeria showed that those mothers with the current history of child related abnormal birth outcome are at greater risk of giving birth to a baby with abnormal outcome (28-29). Similar findings were previously reported in Ethiopia $(16,19$ and 20). The link may be explained in terms of the fact that the complications that have occurred during pregnancy have affected the wellbeing of the fetus in the uterus. 
Mothers who have no support during child bearing had five times chance to develop adverse birth outcome when compared with mothers who have partner support. This study was in line with the study done in united states women with a supportive partner were $63 \%$ less likely to experience LBW and nearly two times less likely to have pregnancy loss compared to those with no partner support (30). This might be those who have paternal support may experience less stress and be more likely to enter prenatal care and they also may be more likely to indicate a desired pregnancy which may reduce their risk of poor birth outcomes.

Inter-pregnancy interval is also found to be a determinant of $A B O$ s. The odd of having ABOs was 1.57 times more likely to among those mothers with short birth interval as compared to optimal spacers. This result is in line with studies in united states, China, Tanzania ,Bangladesh, Mekele, (31-34, and 25), in which short inter-pregnancy interval was a risk factor for low birth weight and/or preterm birth. This could be due to the fact that short inter-pregnancy interval results in maternal nutrition reduction which compromises the mother's ability to support fetal growth and development which in turn increases the risks of preterm birth, growth restriction as well as maternal morbidity and mortality in the subsequent pregnancy.

The study result showed that the new borns who does not get initial new born care had two times chance to experience adverse birth outcomes compared to their counterparts, In this study having current obstetric complication was three times more likely to develop adverse birth outcome when compared with no history of current complication. This result is supported with studies conducted in Gondar, Hosanna, Utah India (13, 19 and 22)

\section{Conclusions}

The result revealed that residence, lack of family support during child bearing, Pregnancy type, short inter pregnancy interval, not provided first initial newborn care, having current obstetric complications and Number of ANC visit were identified as determinants of adverse birth outcome. Therefore, improving family support, inter-pregnancy interval through family planning counseling and provision, providing all initial newborn cares and having the recommended ANC follow-up were recommended.

\section{Abbreviations}

ABO Adverse birth outcome

ANC: Antenatal care

AOR: Adjusted odds ratio

Cl: Confidence interval

COR: Crude odds ratio 
GA: Gestational age

LBW: Low birth weight

PTB: Preterm birth

SD: Standard deviation

WHO: World Health Organization?

MM Maternal mortality

\section{Declarations}

\section{Ethics approval and consent to participate}

Ethical clearance and approval letter to conduct study was obtained from Ambo university institutional review board and a letter of cooperation was taken from the Ambo university institute of health to west shewa health bureau. Written consent was obtained from the study participants after explaining the study objectives and procedures and their right to refuse not to participate in the study any time they want was assured. For this very purpose, a one-page consent letter was attached to the cover page of each questionnaire stating about the general objective of the study and issues of confidentiality which was discussed by the data collectors before proceeding with the interview. Confidentiality of the information was ensured by coding. Only authorized person was getting access to the raw data collected from the field.

\section{Consent for publication}

Not applicable.

\section{Availability of data and materials}

Full data for this research is available through the corresponding author up on request.

\section{Competing interests}

The authors declare that they have no competing interests.

\section{Funding}

Ambo University provide the fund, but has no role and no influence in the design of the study and collection, analysis, and interpretation of data and in writing of the manuscript.

\section{Authors' contributions}


All authors (DB, GA BS, GD and KM) contributed to the design of the study and the interpretation of data. GD performed the data analysis and drafted the manuscript. All others authors critically revised the manuscript and approved the final version. All authors read and approved the final manuscript.

\section{Acknowledgements}

We would like to express our deepest heartfelt thanks west shewa town Health Bureau for providing available information. Our special thanks also go to study participants, data collectors and supervisors

\section{References}

1. Ospina, M., Osornio-Vargas, Á. R., Nielsen, C. C., Crawford, S., Kumar, M., Aziz, K., \& Serrano-Lomelin, J. (2020). Socioeconomic gradients of adverse birth outcomes and related maternal factors in rural and urban Alberta, Canada: A concentration index approach. BMJ Open. https://doi.org/10.1136/bmjopen-2019-033296

2. M.Kliegman, C.J.Rottman REB. Strategies for the prevention of low birth weight. Am J Obstet Gynecol [Internet]. 1990;162(4):1073-83. Available from: http://www.embase.com/search/results? subaction=viewrecord\&from=export\&id=L20155437

3. McCormick, M. C. (1985). The Contribution of Low Birth Weight to Infant Mortality and Childhood Morbidity. New England Journal of Medicine. https://doi.org/10.1056/NEJM198501103120204

4. Barker, D. J. P., Godfrey, K. M., Gluckman, P. D., Harding, J. E., Owens, J. A., \& Robinson, J. S. (1993). Fetal nutrition and cardiovascular disease in adult life. The Lancet. https://doi.org/10.1016/01406736(93)91224-A

5. World Health Organization. (2019). Newborns: reducing mortality. World Health Organization.

6. Kramer MS. Determinants of low birth weight: Methodological assessment and meta-analysis. Bull World Health Organ. 1987;65(5):663-737

7. A., S., G., P., P., N., K., S., A., A., Sadiq, A. A. Puone, T. (2016). Factors associated with adverse pregnancy outcomes and perceptions of risk factors among reproductive age women in Soba LGA, Kaduna State 2013. Pan African Medical Journal.

8. Kramer, M. S. (2003). The epidemiology of adverse pregnancy outcomes: An overview. Journal of Nutrition. https://doi.org/10.1093/jn/133.5.1592s

9. Chang, S. C., O'Brien, K. O., Nathanson, M. S., Mancini, J., \& Witter, F. R. (2003). Characteristics and risk factors for adverse birth outcomes in pregnant black adolescents. Journal of Paediatrics. https://doi.org/10.1067/S0022-3476(03)00363-9

10. Loomans, E. M., Van Dijk, A. E., Vrijkotte, T. G. M., Van Eijsden, M., Stronks, K., Gemke, R. J. B. J., \& Van Den Bergh, B. R. H. (2013). Psychosocial stress during pregnancy is related to adverse birth outcomes: Results from a large multi-ethnic community-based birth cohort. European Journal of Public Health. https://doi.org/10.1093/eurpub/cks097 
11. Tsegaye, Oljira L, Dessie Y, Gebremedhin M, Wakgari N. Adverse Birth Outcome and Associated Factors among Newborns Delivered In Public hospital. East African J Heal Biomed Sci. 2019;3(2):35-44.

12. Adane, A. A., Ayele, T. A., Ararsa, L. G., Bitew, B. D., \& Zeleke, B. M. (2014). Adverse birth outcomes among deliveries at Gondar University Hospital, Northwest Ethiopia. BMC Pregnancy and Childbirth. https://doi.org/10.1186/1471-2393-14-90

13. A., A., T.A., A., L.G., A., B.D., B., \& B.M., Z. (2014). Adverse birth outcomes among deliveries at Gondar University Hospital, Northwest Ethiopia. BMC Pregnancy and Childbirth.

14. Woday, A., Muluneh, M. D., \& Sherif, S. (2019). Determinants of preterm birth among mothers who gave birth at public hospitals in the Amhara region, Ethiopia: A case-control study. PLOS ONE. https://doi.org/10.1371/journal.pone.0225060

15. Gedefaw, G., Alemnew, B., \& Demis, A. (2020). Adverse fetal outcomes and its associated factors in Ethiopia: A systematic review and meta-analysis. BMC Pediatrics. https://doi.org/10.1186/s12887020-02176-9

16. Cherie, N., \& Mebratu, A. (2017). Adverse Birth Out Comes and Associated Factors among Delivered Mothers in Dessie Referral Hospital, North East Ethiopia. Nursing and Health Care. https://doi.org/10.33805/2573-3877.121

17. Lin, L., Wei, Y., Zhu, W., Wang, C., Su, R., Feng, H., \& Yang, H. (2018). Prevalence, risk factors and associated adverse pregnancy outcomes of anaemia in Chinese pregnant women: A multicentre retrospective study. BMC Pregnancy and Childbirth. https://doi.org/10.1186/s12884-018-1739-8

18. Gebremeskel, F., Teklemariam, G., Gemechu, K., Desta, H., \& Yinager, W. (2017). Determinants of Adverse Birth Outcome among Mothers who Gave Birth at Hospitals in Gamo Gofa Zone, Southern Ethiopia: A Facility Based Case Control Study. Quality in Primary Care.

19. RA, A., \& TB, E. (2016). Prevalence and associated Factors of Adverse Birth Outcomes among Women Attended Maternity Ward at Negest Elene Mohammed Memorial General Hospital in Hosanna Town, SNNPR, Ethiopia. Journal of Women's Health Care. https://doi.org/10.4172/21670420.1000324

20. Kassahun, E. A., Mitku, H. D., \& Getu, M. A. (2019). Adverse birth outcomes and its associated factors among women who delivered in North Wollo zone, northeast Ethiopia: A facility based crosssectional study. BMC Research Notes. https://doi.org/10.1186/s13104-019-4387-9

21. Mbuagbaw, L. C. E., \& Gofin, R. (2011). A new measurement for optimal antenatal care: Determinants and outcomes in Cameroon. Maternal and Child Health Journal. https://doi.org/10.1007/s10995010-0707-3

22. Mumbare, S. S., Maindarkar, G., Darade, R., Yengl, S., Tolani, M. K., \& Patole, K. (2012). Maternal risk factors associated with term low birth weight neonates: A matched-pair case control study. Indian Pediatrics. https://doi.org/10.1007/s13312-012-0010-z

23. Ngwira, A. (2019). Spatial quantile regression with application to high and low child birth weight in Malawi. BMC Public Health. https://doi.org/10.1186/s12889-019-7949-9 
24. Baye Mulu, G., Gebremichael, B., Wondwossen Desta, K., Adimasu Kebede, M., Asmare Aynalem, Y., \& Bimirew Getahun, M. (2020). <p>Determinants of Low Birth Weight Among Newborns Delivered in Public Hospitals in Addis Ababa, Ethiopia: Case-Control Study</p>. Pediatric Health, Medicine and Therapeutics. https://doi.org/10.2147/phmt.s246008

25. T., H., G.T., D., H.B., A., M.G., W., \& K.H., M. (2020). Determinants of adverse birth outcome in Tigrai region, North Ethiopia: Hospital-based case-control study. BMC Pediatrics. https://doi.org/10.1186

26. Asmare, G., Berhan, N., Berhanu, M., \& Alebel, A. (2018). Determinants of low birth weight among neonates born in Amhara Regional State Referral Hospitals of Ethiopia: Unmatched case control study. BMC Research Notes. https://doi.org/10.1186/s13104-018-3568-2

27. Gizaw, B., \& Gebremedhin, S. (2018). Factors associated with low birthweight in North Shewa zone, Central Ethiopia: Case-control study. Italian Journal of Pediatrics. https://doi.org/10.1186/s13052018-0516-7

28. Jammeh, A., Sundby, J., \& Vangen, S. (2011). Maternal and obstetric risk factors for low birth weight and preterm birth in rural Gambia: a hospital-based study of 1579 deliveries. Open Journal of Obstetrics and Gynecology. https://doi.org/10.4236/ojog.2011.13017

29. Agrawal, V., Agrawal, P., Chaudhary, V., Agarwal, K., \& Agarwal, A. (2011). Prevalence and determinants of "low birth weight" among institutional deliveries. Annals of Nigerian Medicine. https://doi.org/10.4103/0331-3131.92950

30. Shah MK, Gee RE, Theall KP. Partner support and impact on birth outcomes among teen pregnancies in the United States. J Pediatr Adolesc Gynecol. 2014;27 (1):14-19. doi: 10.1016/j.jpag.2013.08.002

31. Ihongbe, T. O., Wallenborn, J. T., Rozario, S., \& Masho, S. W. (2018). Short interpregnancy interval and adverse birth outcomes in women of advanced age: a population-based study. Annals of Epidemiology. https://doi.org/10.1016/j.annepidem.2018.06.007

32. Lin J, Liu H, Wu DD, et al. Long interpregnancy interval and adverse perinatal outcomes: A retrospective cohort study. Sci China Life Sci. 2020

33. Mahande, M. J., \& Obure, J. (2016). Effect of interpregnancy interval on adverse pregnancy outcomes in northern Tanzania: A registry-based retrospective cohort study. BMC Pregnancy and Childbirth. https://doi.org/10.1186/s12884-016-0929-5

34. C.C., de J., K., A., N., S., A., K., S., S., J., B., T.A.J., H. (2014). Determinants and consequences of short birth interval in rural Bangladesh: A cross-sectional study. BMC Pregnancy and Childbirth.

\section{Tables}

Table 1.Socio-demographic characteristics of mothers who gave birth in public hospitals, West shewa, Ethiopia, 2020 


\begin{tabular}{|c|c|c|}
\hline Variables & Cases (\%) & Control (\%) \\
\hline \multicolumn{3}{|l|}{ Age categories } \\
\hline 25 & $64(10.8 \%)$ & $211(35.7 \%)$ \\
\hline $26-29$ & $29(4,9 \%)$ & $91(15.4 \%)$ \\
\hline $30_{+}$ & $53(9.0 \%)$ & $143(24.2 \%)$ \\
\hline \multicolumn{3}{|l|}{ Religion } \\
\hline Orthodox & $45(7.6 \%)$ & $150(25.4 \%)$ \\
\hline Muslim & $8(1.4 \%)$ & $39(6.6 \%)$ \\
\hline Protestant & $93(15.7 \%)$ & $256(43.35 \%)$ \\
\hline \multicolumn{3}{|l|}{ Ethnicity } \\
\hline Oromo & $138(23.4 \%)$ & $417(70.6 \%)$ \\
\hline Amhara & $8(1.4 \%)$ & $27(4.6 \%)$ \\
\hline Gurage & - & $1(0.2 \%)$ \\
\hline \multicolumn{3}{|l|}{ Occupation of mother } \\
\hline Civil servant & $22(3.7 \%)$ & $74(12.5 \%)$ \\
\hline Private employee & $12(2.0 \%)$ & $38(6.4 \%)$ \\
\hline Farmers & $48(8.1 \%)$ & $124(21.0 \%)$ \\
\hline Merchant & $19(3.2 \%)$ & $54(9.1 \%)$ \\
\hline House wife & $45(7.6 \%)$ & $155(26.2 \%)$ \\
\hline \multicolumn{3}{|l|}{ Occupation of husband } \\
\hline Civil servant & $37(6.3 \%)$ & $136(23.0 \%)$ \\
\hline Private employee & $14(2.4 \%)$ & $61(10.3 \%)$ \\
\hline Farmers & $68(11.5 \%)$ & $175(29.6 \%)$ \\
\hline Merchant & $27(4.6 \%)$ & $73(12.4 \%)$ \\
\hline \multicolumn{3}{|l|}{ Educational status of mother } \\
\hline Unable to read and write & $45(7.6 \%)$ & $151(25.5 \%)$ \\
\hline Primary education (1-8) & $51(8.6 \%)$ & 114(19.3\%) \\
\hline Secondary education (9-12) & $25(4.2 \%)$ & $89(15.1 \%)$ \\
\hline Collage and above & $25(4.2 \%)$ & $91(15.4 \%)$ \\
\hline
\end{tabular}




\begin{tabular}{|lll|}
\hline Educational status of husband & & \\
\hline Unable to read and write & $32(5.4 \%)$ & $108(18.3 \%)$ \\
\hline Primary education (1-8) & $50(8.5 \%)$ & $99(16.8 \%)$ \\
\hline Secondary education (9-12) & $30(5.1 \%)$ & $108(18.3 \%)$ \\
\hline Collage and above & $34(5.8 \%)$ & $130(22.0 \%)$ \\
\hline Monthly income & & \\
\hline$<1000$ & $73(12.4 \%)$ & $164(27.7 \%)$ \\
\hline $1001-3000$ & $41(6.9 \%)$ & $139(23.5 \%)$ \\
\hline $3000+$ & $32(5.4 \%)$ & $142(24.0 \%)$ \\
\hline Residence & & \\
\hline Rural & $84(14.2 \%)$ & $170(28.8 \%)$ \\
\hline Urban & $62(10.5 \%)$ & $275(46.5 \%)$ \\
\hline
\end{tabular}

Table 2 Obstetric characteristics of mothers who gave birth in public hospitals, West shewa, Ethiopia, 2020. 


\begin{tabular}{|c|c|c|}
\hline \multirow[t]{2}{*}{ Variables } & Cases 197 & Control 394 \\
\hline & N\% & $\mathrm{N} \%$ \\
\hline \multicolumn{3}{|c|}{ Number of pregnancy } \\
\hline$<=1$ & $49(8.3 \%)$ & $184(31.1 \%)$ \\
\hline $2-3$ & $52(8.8 \%)$ & $146(24.7 \%)$ \\
\hline$>=4$ & $45(7.6 \%)$ & $115(19.5 \%)$ \\
\hline \multicolumn{3}{|l|}{ ANC } \\
\hline Yes & $117(19.8 \%)$ & $383(64.8 \%)$ \\
\hline No & $29(4.9 \%)$ & $62(10.5 \%)$ \\
\hline \multicolumn{3}{|c|}{ Number of ANC visit } \\
\hline$<4$ & $100(16.9 \%)$ & $243(41.1 \%)$ \\
\hline$>4$ & $46(7.8 \%)$ & $202(34.2 \%)$ \\
\hline \multicolumn{3}{|c|}{ Planned pregnancy } \\
\hline Yes & $118(20 \%)$ & $371(62.8 \%)$ \\
\hline No & $28(4.7 \%)$ & $74(12.5 \%)$ \\
\hline \multicolumn{3}{|c|}{ Family planning use } \\
\hline Yes & 104(17.6\%) & $288(48.7 \%)$ \\
\hline No & $42(7.1 \%)$ & $157(26.6 \%)$ \\
\hline \multicolumn{3}{|c|}{ Medical disorder } \\
\hline Yes & $19(5.2 \%)$ & $27(7.4 \%)$ \\
\hline No & $80(22 \%)$ & $238(65.4 \%)$ \\
\hline \multicolumn{3}{|c|}{ History of obstetrics complication } \\
\hline Yes & $11(3 \%)$ & $30(8.3 \%)$ \\
\hline No & $88(24.4 \%)$ & $232(64.3 \%)$ \\
\hline \multicolumn{3}{|c|}{ Current Obstetrics complication } \\
\hline Yes & $22(3.7 \%)$ & $37(6.3 \%)$ \\
\hline No & $124(21 \%)$ & $408(69 \%)$ \\
\hline \multicolumn{3}{|l|}{ Sex } \\
\hline Male & $86(14.6 \%)$ & $289(48.9 \%)$ \\
\hline
\end{tabular}




\begin{tabular}{|lll|}
\hline female & $58(9.8 \%)$ & $151(25.5 \%)$ \\
\hline Twins, one male, one female & $2(0.3 \%)$ & $5(0.8 \%)$ \\
\hline
\end{tabular}

Table 3 Bivariate and multivariate logistic regression analysis of determinants of adverse birth outcome. 


\begin{tabular}{|c|c|c|c|c|c|}
\hline \multirow[t]{2}{*}{ Variables } & \multicolumn{2}{|c|}{ Adverse birth outcome } & \multirow[t]{2}{*}{ COR95\%Cl } & \multirow[t]{2}{*}{ AOR95\%Cl } & \multirow[t]{2}{*}{ p-value } \\
\hline & Yes & No & & & \\
\hline \multicolumn{6}{|c|}{ Residence } \\
\hline Urban & $62(10.5 \%)$ & $275(46.6 \%)$ & $0.456(0.312,0.667)$ & $0.56(0.36-0.88) \star$ & 0.011 \\
\hline Rural & $84(14.2 \%)$ & $170(28.8 \%)$ & 1 & 1 & \\
\hline \multicolumn{6}{|c|}{ Family support during child bearing } \\
\hline No & $85(14.4 \%)$ & $406(68.7 \%)$ & 7.471(4.693-11.893) & $5.07(3.01-8.54) \star$ & .000 \\
\hline Yes & $61(10.3 \%)$ & $39(6.6 \%)$ & 1 & 1 & \\
\hline \multicolumn{6}{|c|}{ Pregnancy type } \\
\hline Twins & $32(5.2 \%)$ & $26(4.4 \%)$ & $4.524(2.591-7.899)$ & $3.99(2.04-7.83) \star$ & 0.000 \\
\hline Single & $114(19.3 \%)$ & $419(70.9 \%)$ & 1 & 1 & \\
\hline \multicolumn{6}{|c|}{ Birth interval } \\
\hline$<2$ years & $99(16.8 \%)$ & $206(34.9 \%)$ & $2.444(1.648-3.624)$ & $1.57(1.99-2.48) \star$ & 0.0001 \\
\hline$>2$ years & $47(8 \%)$ & $239(40.4 \%)$ & 1 & 1 & \\
\hline \multicolumn{6}{|c|}{ Provided first initial newborn care } \\
\hline No & $56(9.5 \%)$ & $279(47.2 \%)$ & 2.701(1.838-3.969) & $2.19(1.39-3.41)^{\star}$ & 0.001 \\
\hline Yes & $90(15.2 \%)$ & $166(28.1 \%)$ & 1 & 1 & \\
\hline \multicolumn{6}{|c|}{ Number of ANC visit } \\
\hline$<4$ & $100(16.9 \%)$ & $243(41.1 \%)$ & $1.807(1.216-2.685)$ & $1.63(1.02-2.62) \star$ & 0.006 \\
\hline$>=4$ & $46(7.8 \%)$ & $202(34.2 \%)$ & 1 & 1 & \\
\hline \multicolumn{6}{|c|}{ Current obstetrics complication } \\
\hline Yes & 104(17.6\%) & $405(68.5 \%)$ & $4.089(2.521-6.632)$ & $2.74(1.55-4.84) \star$ & 0.000 \\
\hline NO & $42(7.1 \%)$ & $40(6.5 \%)$ & 1 & 1 & \\
\hline
\end{tabular}

Keys: $1=$ Reference category

*Statistically significant at $p<0.05$ in multivariate 